\title{
PENGGUNAAN METODE SIMPLE QUEUE DALAM MANAJEMEN BANDWIDTH
}

\author{
Santoso Setiawan \\ Program Studi Teknik Komputer \\ AMIK BSI Jakarta \\ Jl. RS Fatmawati No.24 Jakarta \\ Indonesia \\ santoso.setiawan@gmail.com
}

\author{
Mirza Maulana \\ Program Studi Teknik Informatika \\ STMIK Nusa Mandiri Jakarta \\ Jl. Kramat Raya No 18 Jakarta \\ Indonesia \\ m_maulana@gmail.com
}

\begin{abstract}
Abstrak - Semakin banyaknya penggunaan aplikasi jaringan komputer antar kantor cabang, akan memudahkan organisasi dengan banyak kantor cabang untuk berkolaborasi, namun tidak semua aplikasi bisa di lewatkan jalur internet, dengan mempertimbangkan aspek keamanan atau memang akibat keterbatasan dari aplikasi itu sendiri. Untuk itulah digunakan metode EoIP untuk menghubungkan dua atau lebih kantor suatu organisasi dengan biaya relatif lebih murah dari sewa VPN-IP, dengan memanfaatkan jaringan ADSL (public network/internet). Fitur ini akan membridge jaringan antar kantor cabang dengan melewati jaringan publik (internet).
\end{abstract}

Kata Kunci: EoIP tunneling, Mikrotik, VPN

\section{PENDAHULUAN}

Penggunaan bandwidth dan manajemen bandwidth pada suatu perusahaan sangat diperlukan, sebab apabila perusahaan tidak melakukan manajemen bandwidth maka lalu lintas data internet pada perusahaan tersebut tidak akan efisien penggunaannya.

Sebuah jaringan memerlukan pemakaian manajemen bandwidth yang baik, sehingga dapat mengatur lalu lintas data tepat sasaran (Afdhal, dkk, 2010:69). Implementasi mikorotik router dapat mengatur lalu lintas data internet serta melakukan pemfilteran beberapa aplikasi yang dapat mengganggu konektifitas jaringan komputer sesuai dengan aturan yang telah ditetapkan dan disepakati bersama.

Dengan mengatur pembagian bandwidth sesuai kebutuhan, diharapkan dapat mengoptimalkan penggunaan bandwidth internet yang sangat terbatas (Abdullah, dkk, 2014:36). Konsep dasar untuk mengimplementasikan manajemen trafik dan bandwidth internet dapat dilihat dari bandwidth dan trafik, thoughput, dan quality of service. Bandwidth dan troughput dapat ditentukan dengan faktor berikut piranti jaringan, tipe data yang di transfer, topologi jaringan, banyaknya pengguna jaringan, spesifikasi komputer klien/user, spesifikasi komputer server, induksi listrik dan cuaca.

\section{LANDASAN TEORI}

\section{A. Konsep Dasar Jaringan}

Jaringan komputer adalah kumpulan beberapa komputer (dan perangkat lain seperti router, switch dan sebagainya) yang saling terhubung satu sama lain melalui media perantara. Media perantara ini bisa berupa media kabel ataupun media tanpa kabel (nirkabel). Informasi berupa data akan mengalir dari satu komputer ke komputer lainnya atau dari satu komputer ke perangkat yang lain, sehingga masing-masing komputer yang terhubung tersebut bisa berbagi sumber daya (Sofana, 2013:3)

\section{B. Interkoneksi Antar Node/Komputer}

Menurut Kustanto dan Saputro (2015:3) menjelaskan bahwa interkoneksi antar node/komputer adalah sistem koneksi/hubungan antara komputer satu dengan yang lainya. Model interkoneksi antar node/komputer di bedakan menjadi dua bagian yaitu:

1. Interkoneksi point to point

Interkoneksi komputer yang dilakukan secara langsung antara dua komputer (node)

2. Interkoneksi multipoint"

Interkoneksi yang di lakukan dengan bantak komputer dengan pemakaian secara bersamaan (teknik share).

\section{IP Address}

IP Address adalah pengenalan yang unik yang membedakan antara komputer satu dengan komputer yang lainnya dalam jaringan. Setiap IP Address dibutuhkan untuk setiap komputer dan komponen jaringan seperti router, komunikasinya menggunakan TCP/IP (Sukaridhoto, 2014:7). Alamat TCP/IP terdiri atas bagian Network ID dan Host ID. Network ID berfungsi untuk mengindetifikasikan suatu jaringan dari jaringan yang lain. Host ID berfungsi untuk mengindetifikasi host dalam suatu jaringan.

\section{Topologi Jaringan}

Ada beberapa jenis jaringan yang dikelompokkan berdasarkan topologi (Sutanta, 2009:7) :

- Topologi Bus

- Topologi Star

- Topologi Ring

- Topologi Mesh

\section{E. Simple Queue}

Mekanisme pengaturan bandwidth dengan tujuan mencegah terjadinya monopoli penggunaan bandwidth sehingga semua client bisa mendapatkan jatah bandwidth masing-masing (Irawan, 2017:1). QoS (Quality of Services) atau dikenal dengan lebih bandwidth management, merupakan metode yang digunakan untuk 
memenuhi kebutuhan tersebut. Pada RouterOS Mikrotik penerapan QoS (Quality Of Service) bisa dilakukan dengan fungsi Queue.

\section{METODE PENELITIAN}

Dalam penulisan ini, metode penelitian yang digunakan adalah sebagai berikut:

\section{A. Analisa Kebutuhan}

Kebutuhan untuk dibangunnya manajemen bandwidth guna untuk membatasi penggunaan internet biasanya menggunakan kuota bandwidth yang terbatas dari ISP, user yang terkoneksi ke router mikrotik, WinBox mikrotik, dan fitur queue pada router mikrotik.

\section{B. Desain}

Pada tahap ini penulis melakukan perancangan topologi jaringan yang akan di bangun dan di lanjutkan dengan mengkonfigurasi komputer yang bertugas sebagai server yaitu melakukan manajemen bandwidth dari Internet Service Provider (ISP) untuk digunakan oleh user. Setelah dilakukannya konfigurasi pada komputer yang bertugas menjadi server maka langkah selanjutnyaa dalah penentuan IP Address. Penentuan IP Address ini bertujuan untuk mendaftarkan IP Address mana saja yang akan digunakan untuk browsing. Selanjutnya melakukan konfigurasi aturan untuk menentukan maksimal bandwidth dan limit yang akan diterapkan.

\section{Testing}

Setelah simple queue berhasil dibuat, maka kita dapat melakukan pengujian dengan melakukan download dari komputer client yang akan di uji. Apabila pada queue terpantau warna merah berarti client tersebut telah mencapai batas limit bandwidth yang telah di setting dan jika berwarna kuning berarti client tersebut sudah mendekati batas limit bandwidth.

\section{Implementasi}

Untuk implementasi dapat dilakukan setelah semua konfigurasi telah selesai dilakukan.implementasi dilakukan dengan menggunakan WinBox sebagai salah satu tools yang digunakan untuk melihat atau mengamati sistem yang akan diterapkan.

Sebelum masuk kedalam WinBox terdapat sebuah interface yang harus dilakukan untuk diisi dengan IP Address dan login. IP Address berfungsi sebagai jalur untuk masuk kedalam WinBox, serta login berfungsi untuk masuk kedalam WinBox sebagai admin. Selain itu untuk menggunakan WinBox dibutuhkan koneksi internet.

\section{HASIL DAN PEMBAHASAN}

Penelitian ini dilakukan pada PT. Kepuh Kencana Arum yang berlokasi di Jakarta. Perusahaan bergerak di bidang manufacturing atap metal gelombang. Seiring berjalannya waktu dan perkembangan perusahaan yang lumayan pesat sampai sekarang PT. Kepuh Kencana Arum telah menggunakan banyak komputer yang terhubung jaringan.

\section{A. Topologi Jaringan}

Topologi yang digunakan pada PT. Kepuh Kencana Arum adalah topologi star. Semua perangkat jaringan baik client maupun server terhubung ke jaringan melalui perangkat switch yang berfungsi sebagai sentral jaringan.

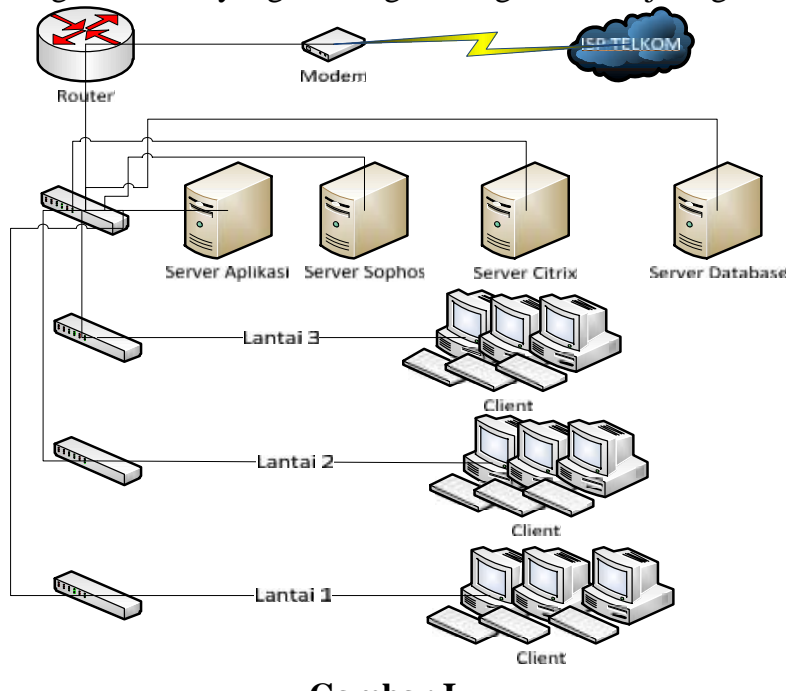

Gambar I

Topologi Jaringan PT. Kepuh Kencana Arum

\section{B. Skema Jaringan}

Sistem jaringan komputer pada PT. Kepuh Kencana Arum menggunakan Simple Queue pada MikroTik sebagai manajemen bandwidthnya. Pembagian bandwitdh pada client dari skema jaringan pada PT. Kepuh Kencana Arum dapat dilihat sebagai berikut:

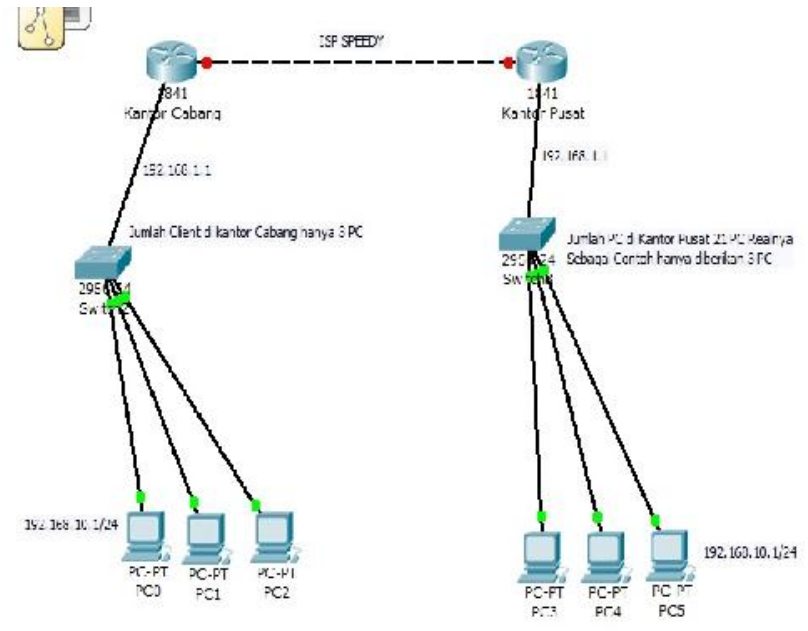

Gambar II

Skema Jaringan PT. Kepuh Kencana Arum

\section{Rancangan Aplikasi}

Skenario yang digunakan adalah jaringan lokal yang memiliki alokasi bandwidth total 5Mbps .Dengan menggunakan static bandwidth control maka alokasi bandwidth untuk masing-masing client akan tetap. Misalnya client 1 akan mendapatkan alokasi bandwidth yaitu sebesar $1 \mathrm{Mbps}$, begitupun juga dengan client 2. Bila menggunakan WinBox maka konfigurasi dapat dilakukan melalui menu Queue>Simple Queues> Add.

Berikut cara untuk konfigurasi simple quеие di MikroTik dengan metode IP Address. 
a) Tampilan menu GUI di WinBox, kita klik pada bacaan "Queues"

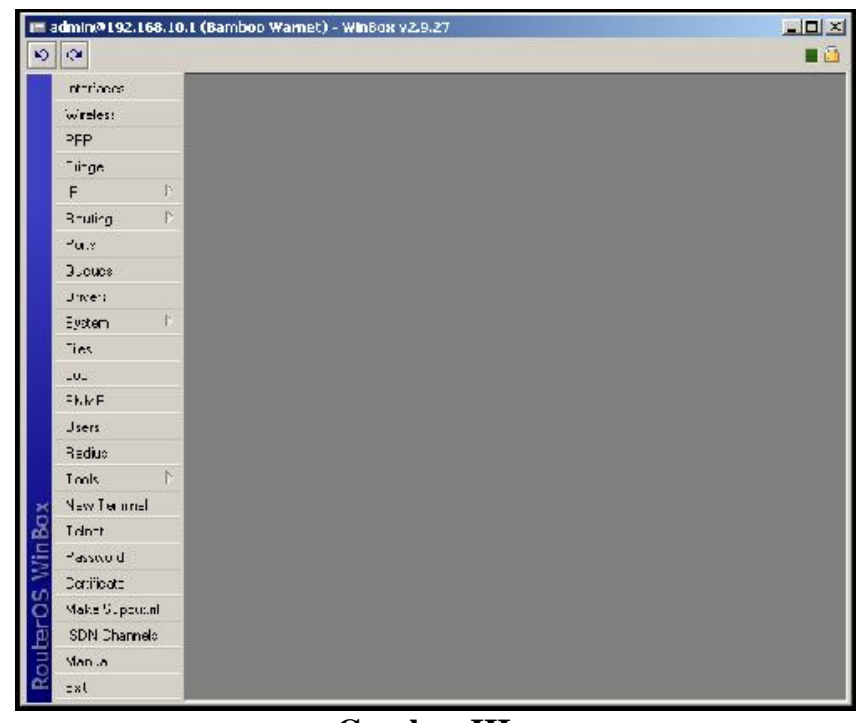

Gambar III

Tampilan Menu GUI di WinBox

b) Pada Queue List, kita pilih Simple Queues

c) Lalu add simple queues dengan mengklik tanda "+"

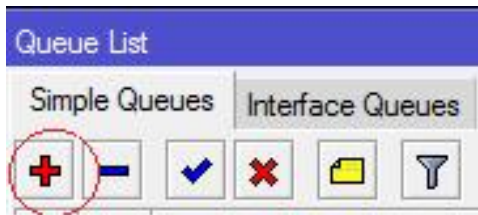

Gambar IV

Tampilan Queue List

d) Pada menu general kita masukkan target network address yang akan di manage bandwidth-nya

e) Isi nama target network sebagai parent, untuk target per IP Address

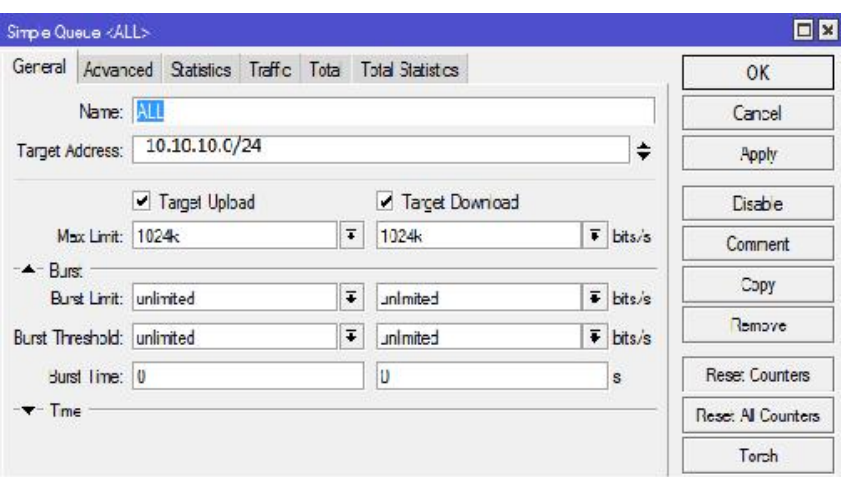

Gambar V

Tambahkan Target Network

f) Lalu buatlah untuk target per IP Address-nya

g) Pada menu General kita masukkan nama dan masukkan target Upload, dan Download

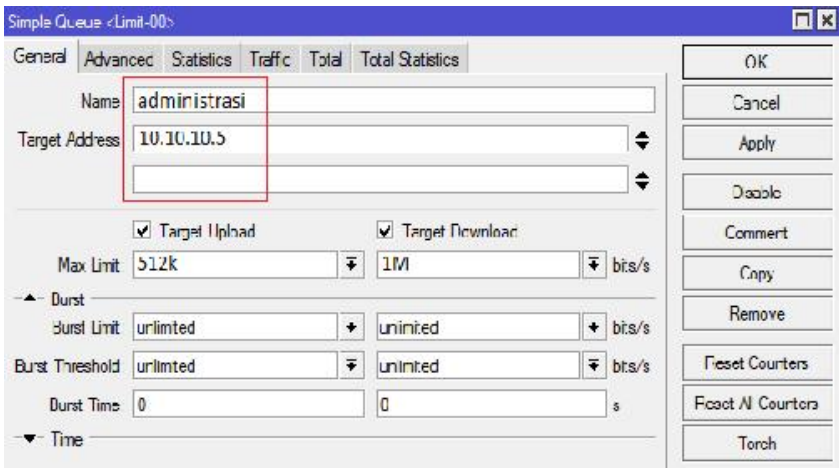

\section{Gambar VI}

Tambahkan Targer Per IP Address

h) Masukkan nama Parent yang telah dibuat

i) Pada menu Simple Queue, kita pilih Advanced untuk menunjuk Parent

j) Pilih nama Parent yang telah dibuat

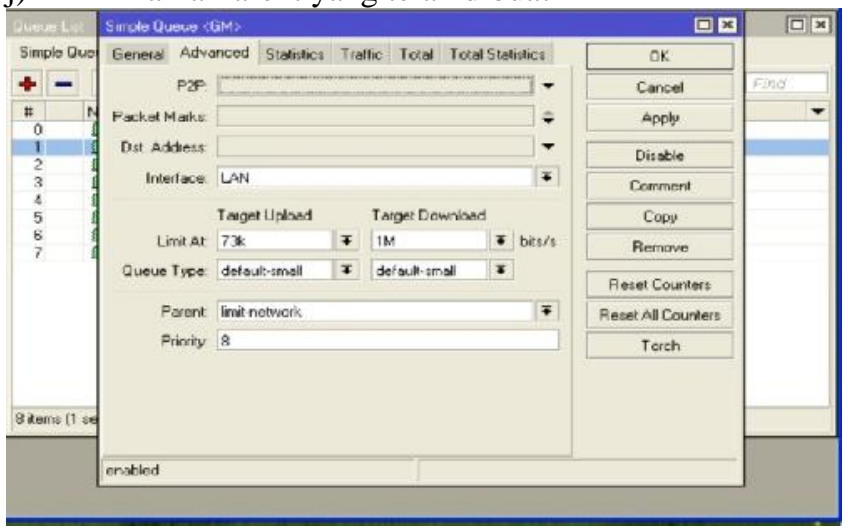

\section{Gambar VII}

Masukkan Nama Parent yang Digunakan

k) Selesai

Berikut contoh konfigurasi Simple Queue per IP Address yang sudah selesai dibuat.

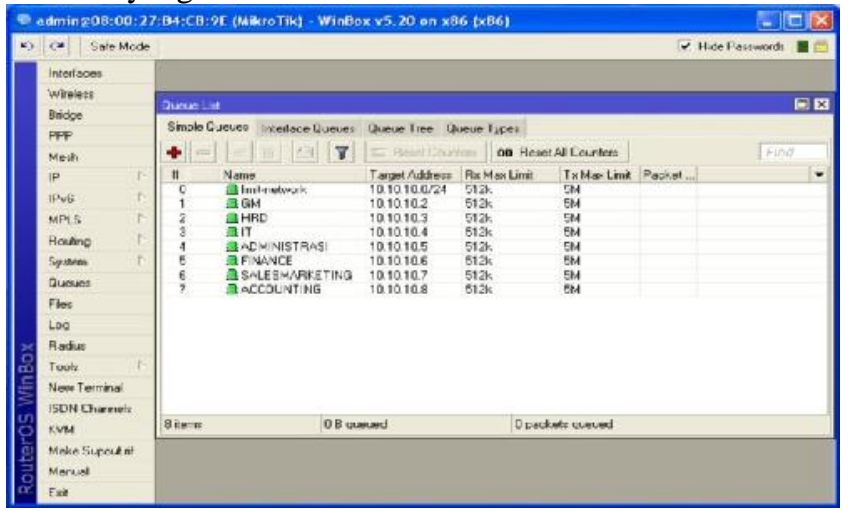

Gambar VIII

Contoh Konfigurasi Per IP Address yang telah selesai Dibuat

\section{Pengujian Jaringan}

Pengujian Awal

Ada beberapa kemungkinan yang terjadi dalam jaringan dimana beberapa client mungkin saja melakukan aktifitas yang sama yaitu download atau upload juga melakukan aktifitas yang berbeda dimana beberapa client 
melakukan aktifitas upload sedangkan client yang lain melakukan download. Pengujian dilakukan menggunakan speedtest pada user yang berlaku sebagai client dan berikut adalah gambaran-gambaran real yang terjadi:

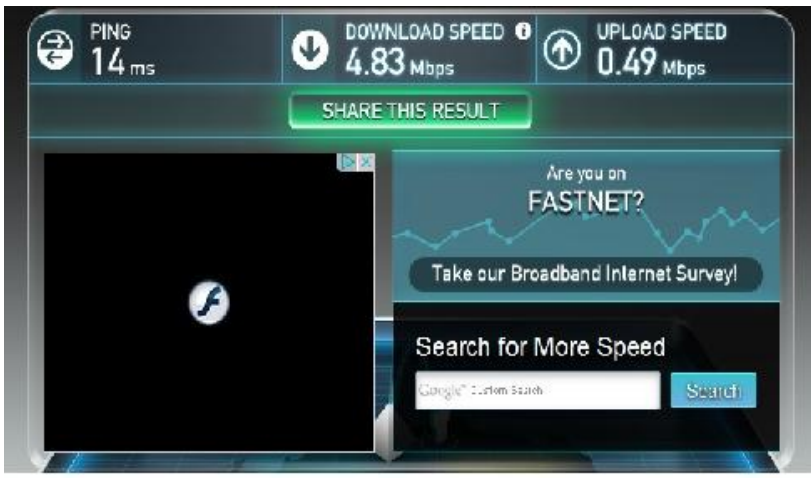

Gambar IX

Hasil Download Sebelum Penerapan Manajemen Bandwidth

Pada kondisi seperti gambar diatas, alokasi bandwidth yang didistribusikan ke $P C$ router adalah sebesar $5 \mathrm{Mbps}$, dimana suatu client melakukan aktifitas download secara bersamaan.

Pengujian Akhir

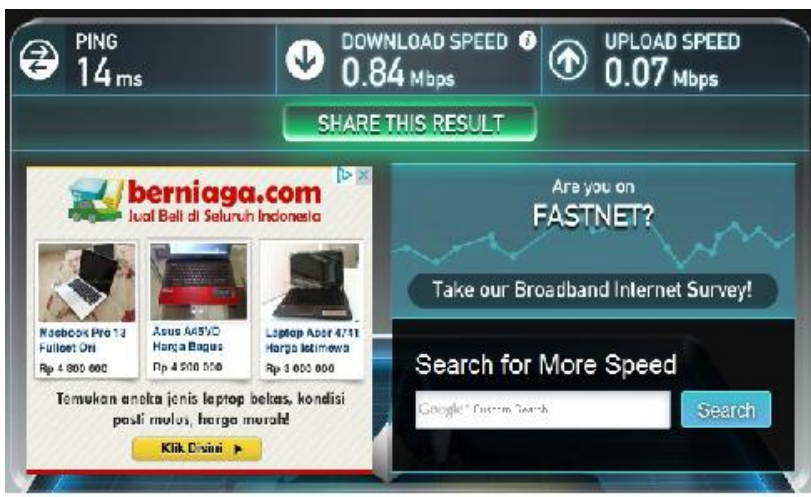

Gambar X

Hasil Download Setelah Penerapan Manajemen Bandwidth Dengan Simple Queue Oleh 2 User Secara Bersamaan

Pada kondisi seperti gambar diatas, menunjukan hasil dari Speedtest pada pengujian akhir. Jika dilihat alokasi bandwidth yang didistribusikanke ke PC client.

\section{KESIMPULAN}

Penggunaan metode simple queue sangat berguna untuk menstabilkan kecepatan internet setiap user pada sebuah perusahaan dikarenakan setiap user mendapatkan hak bandwidth yang dibatasi oleh network administrator yang otomatis user tidak perlu untuk saling berebut penggunaan bandwidth. Selain itu metode simple queue dapat diterapkan sebagai kontrol dan proteksi pada tiap jaringan

\section{DAFTAR PUSTAKA}

Abdullah, Tamam Asrori, Misdiyanto. (2014). Optimalisasi Bandwidth Dengan Filterisasi Menggunakan Mikrotik Routerboard di Universitas Panca Marga Probolinggo. Jurnal Energy. ISSN: 20884591. Probolinggo: Vol. 4 No. 2 Edisi Nopember 2014: 36-46.

Afdhal Afdhal, Taufiq A. Gani, Haimi Ardiansyah. (2010). Pengaturan Pemakaian Bandwidth Menggunakan Mikrotik Bridge. E-ISSN: 2252-620X. Banda Aceh: Jurnal Rekayasa Elektrika Vol. 9, No. 2, Oktober 2010: 69-76.

Irawan, Dodi. (2017). Cara Membuat Simple Queue Mikrotik Otomatis Menggunakan Script. https://www.dodiventuraz.net/2017/12/cara-membuatsimple-queue-mikrotik-secara-otomatis-denganscript.html

Kustanto, Saputro. (2015). Belajar Jaringan Komputer Berbasis Mikrotik OS. Yogyakarta: Gava Media.

Sofana, Iwan. (2010). Cisco CCNA dan Jaringan Komputer. Bandung: Informatika.

Sukaridhoto, Sritrusta. (2014). Buku Jaringan Komputer I. Surabaya. Politeknik Elektronika Negeri Surabaya.

Sutanta, Edhy. (2009). Komunikasi Data dan Jaringan Komputer. Yogyakarta: Graha Ilmu. 